\title{
MaloPlatin-B, a Cisplatin-based BODIPY-tagged Mito-Specific "Chemo-PDT" Agent Active in Red Light
}

Vanitha Ramu, ${ }^{\dagger}$ Paramita Kundu, ${ }^{*}$ Paturu Kondaiah, ${ }^{*} *$ and Akhil R. Chakravarty ${ }^{\dagger *}$

${ }^{\dagger}$ Department of Inorganic and Physical Chemistry, e-mail: arc@iisc.ac.in

and Department of Molecular Reproduction, Development and Genetics, Indian Institute of Science, Bangalore 560012, India. e-mail: paturu@iisc.ac.in 


\section{$\underline{\text { Table of Contents }}$}

\section{Experimental Section}

Scheme S1. Synthetic scheme for the ligand HA-BOD

Scheme S2. Synthetic scheme for the complex Pt-A-BOD

Figure S1. Mass spectrum of ligand HA-BOD in $\mathrm{MeOH}$

Figure S2. Mass spectrum of complex Pt-A-BOD in $\mathrm{MeOH}$

Figure S3. ${ }^{1} \mathrm{H}$ NMR spectrum of ligand HA-BOD in $\mathrm{CDCl}_{3}$

Figure S4. ${ }^{1} \mathrm{H}$ NMR spectrum of complex Pt-A-BOD in DMSO- $\mathrm{d}_{6}$

Figure S5. ${ }^{13} \mathrm{C}$ NMR spectrum of ligand $\mathrm{HA}-\mathrm{BOD}$ in $\mathrm{CDCl}_{3}$

Figure S6. ${ }^{13} \mathrm{C}$ NMR spectrum of complex Pt-A-BOD in DMSO-d $\mathrm{d}_{6}$

Figure S7. ${ }^{11} \mathrm{~B}$ NMR spectrum of ligand $\mathrm{HA}-\mathrm{BOD}$ in $\mathrm{CDCl}_{3}$

Figure S8. ${ }^{11}$ B NMR spectrum of complex Pt-A-BOD in DMSO-d $\mathrm{d}_{6}$

Figure S9. Time dependent UV-Vis spectra of complexes Pt-A-BOD, Pt-Ac and ligand HABOD in dark and light in 10\% DMSO/DMEM solution

Figure S10. Cell viability plots as obtained from the MTT assay

Figure S11. Cell viability plots as obtained from the MTT assay

Figure S12. Cellular uptake plots of ligand HA-BOD in A549 cells

Figure S13. DCFDA Assay plot of ligand HA-BOD in A549 cells

Figure S14. Scattered plots of complex Pt-A-BOD in A549 cells of confocal images

Figure S15. Confocal microscopic image of ligand HA-BOD in A549 cells

Figure S16. Confocal microscopic images of complex Pt-A-BOD in A549 cells for bleaching studies as a dye.

Table S1. Optimized coordinates of the complex Pt-A-BOD and ligand HA-BOD as obtained from the DFT calculations.

Table S2. Selected Estimated Bond Distances $(\AA)$ and Angles $\left({ }^{\circ}\right)$ for the Complex Pt-A-BOD from DFT study 
Methods for Cellular Experiments: The detailed procedures are followed as per reported in the literature. $^{2}$

MTT Assay: The 3-(4,5-dimethylthiazol-2-yl)-2,5-diphenyltetrazolium bromide (MTT) assay was used for the photocytotoxicity of the compounds. ${ }^{1}$ The detailed procedure is followed as per reported in the literature. ${ }^{2}$

Cellular Localization: By using confocal microscopy, the intracellular localization of the fluorescent compounds was investigated (confocal microscope Zeiss LSM 880 with Airyscan) with an oil immersion lens having a magnification of $63 \mathrm{X}$. The detailed procedure is as per reported in the literature. ${ }^{2}$

DCFDA Study: Cellular reactive oxygen species (ROS) was detected from 2',7'dichlorofluorescein diacetate (DCFDA) assay. ${ }^{2,3}$

Cellular uptake studies by FACS: Cellular uptake of the fluorescent compounds was studied in A549 and HPL1D cells by FACS (fluorescence-activated cell sorting) analysis. ${ }^{2}$

DNA Binding studies: The DNA binding experiments were performed in Tris-HCl buffer (5 mM, pH 7.2) using DMF solution of the complex and calf thymus DNA. he intrinsic binding constant $(\mathrm{Kb})$ of the complexes were obtained by using the expression: [DNA]/( $\left.\varepsilon_{\mathrm{a}}-\varepsilon_{\mathrm{f}}\right)=[\mathrm{DNA}] /$ $\left(\varepsilon_{\mathrm{a}}-\varepsilon_{\mathrm{f}}\right)+1 / \mathrm{Kb}\left(\varepsilon_{\mathrm{a}}-\varepsilon_{\mathrm{f}}\right)$, where [DNA] is the concentration of DNA in base pairs, $\varepsilon f, \varepsilon \mathrm{a}$ and $\varepsilon \mathrm{b}$ are the molar extinction-coefficient values of the free complex in solution, complex bound to DNA at a definite concentration, and the complex in completely DNA bound form, respectively. ${ }^{4}$ 


\section{Synthesis:}
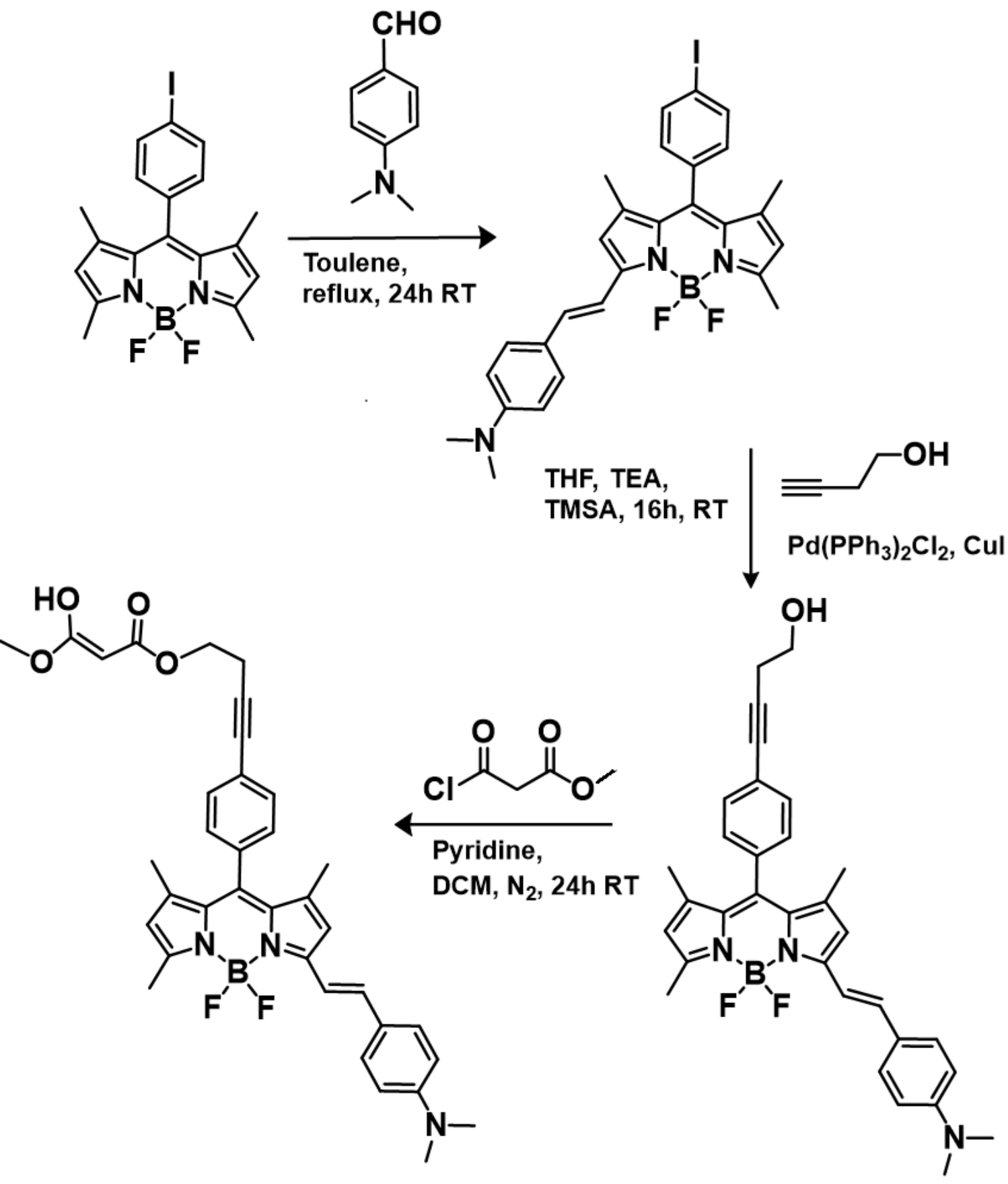

Scheme S1. Synthetic scheme for the ligand HA-BOD with IUPAC name (E)-1-((4-(4-(3-((E)-4(dimethylamino)styryl)-5,5-difluoro-1,7,9-trimethyl-5H-414,514-dipyrrolo[1,2-c:2',1'f][1,3,2]diazaborinin-10-yl)phenyl)but-3-yn-1-yl)oxy)-3-methoxyprop-1-ene-1,3-diol. 


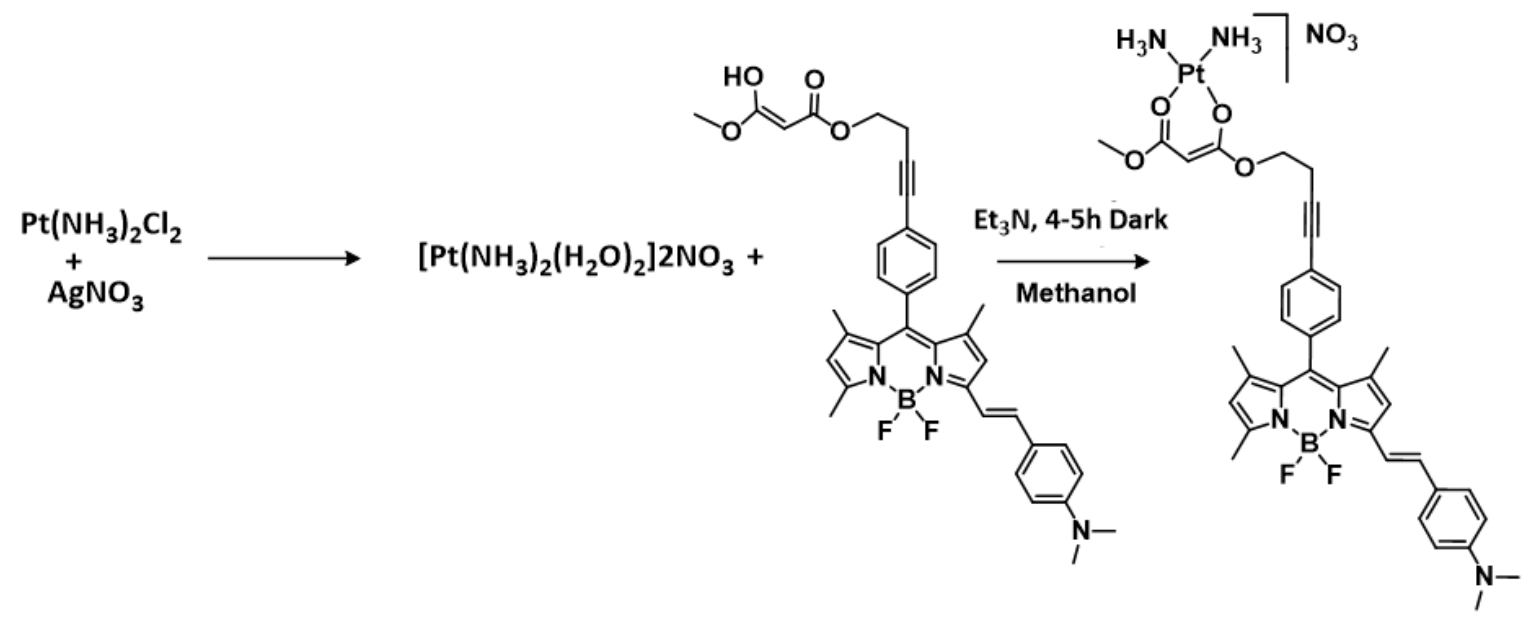

Scheme S2. Synthetic scheme for the complex Pt-A-BOD. 


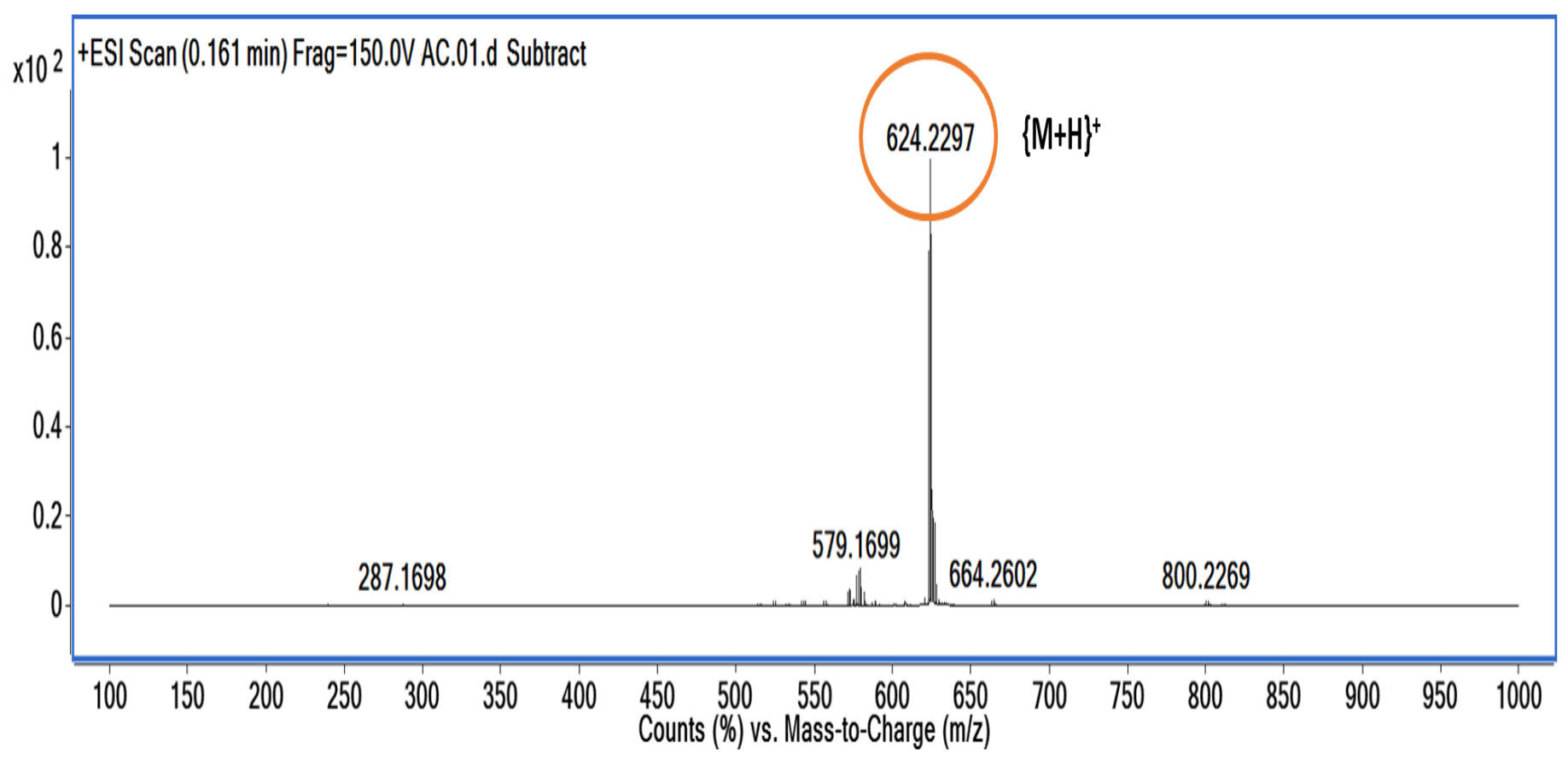

Figure S1. Mass spectrum of ligand HA-BOD in MeOH showing prominent parent ion peak at 624.2297 $(\mathrm{m} / \mathrm{z})$ which corresponds to $[\mathrm{M}+\mathrm{H}]^{+}$. 


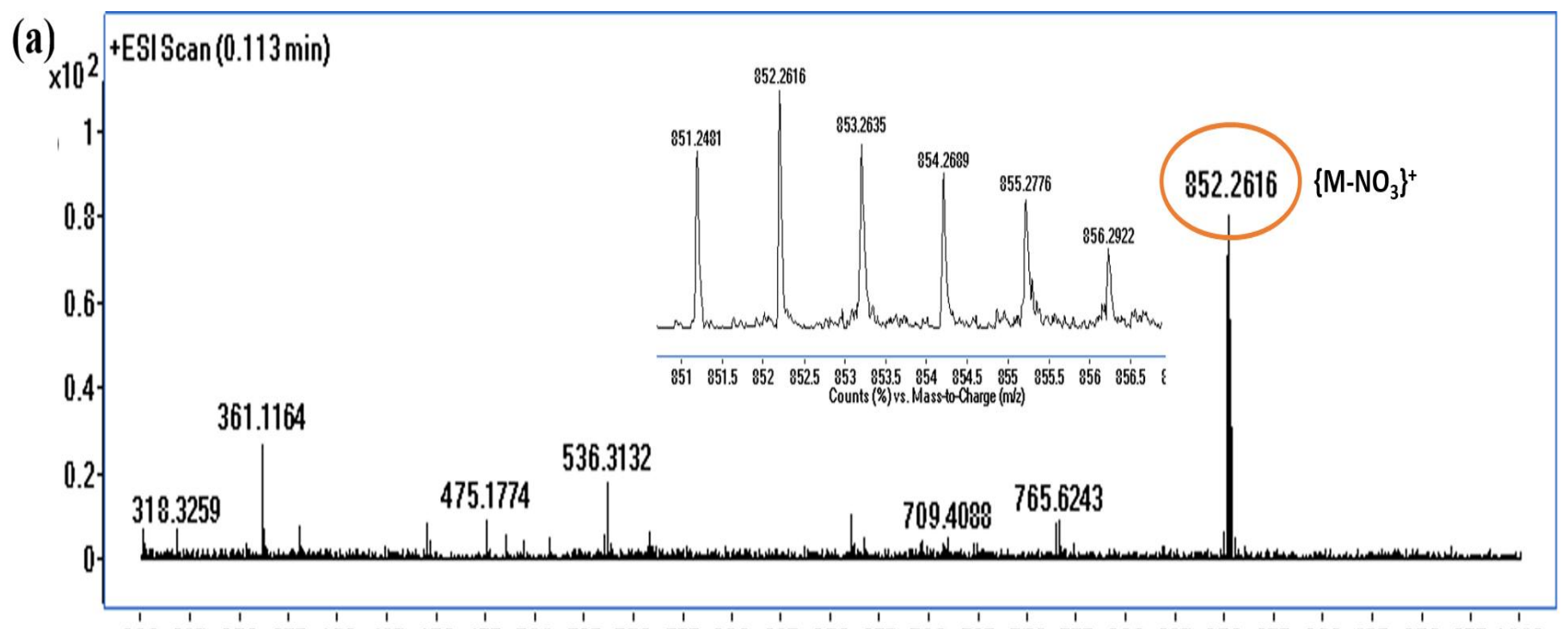

3003253503754004254504755005255505756006256506757007257507758008258508759009259509751000 Counts (\%) vs. Massto-Charge (n/2)

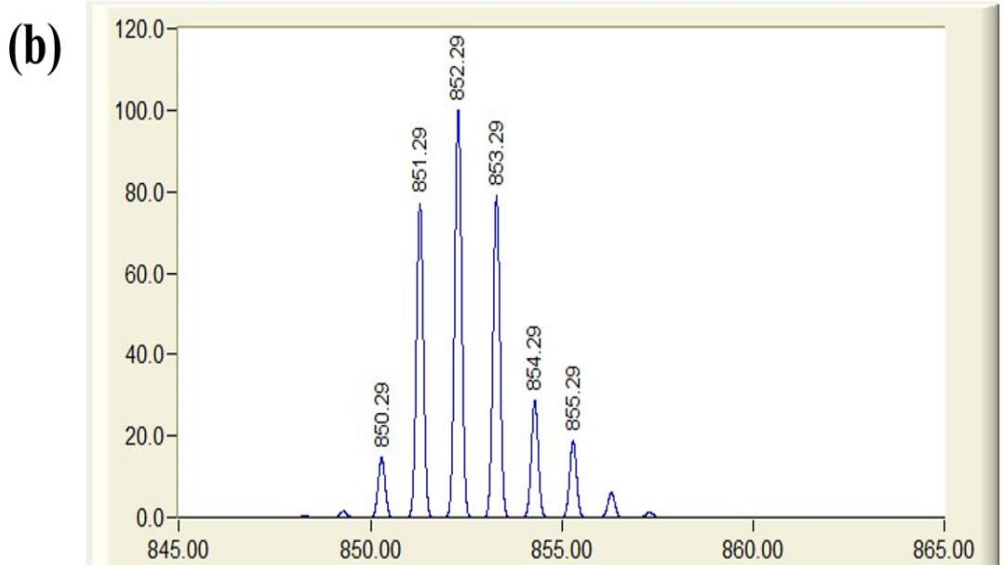

Figure S2: (a) Mass spectrum of complex Pt-A-BOD, $\left[\mathrm{Pt}(\mathrm{A}-\mathrm{BOD})_{2}\left(\mathrm{NH}_{3}\right)_{2}\right]\left(\mathrm{NO}_{3}\right)$, in $\mathrm{MeOH}$ showing prominent parent ion peak at $852.2616(\mathrm{~m} / \mathrm{z})$ which corresponds to $\left[\mathrm{M}-\mathrm{NO}_{3}\right]^{+}$. Inset shows the isotopic distribution pattern for platinum of the molecular ion peak. (b) The computational isotopic distribution for the complex Pt-A-BOD 


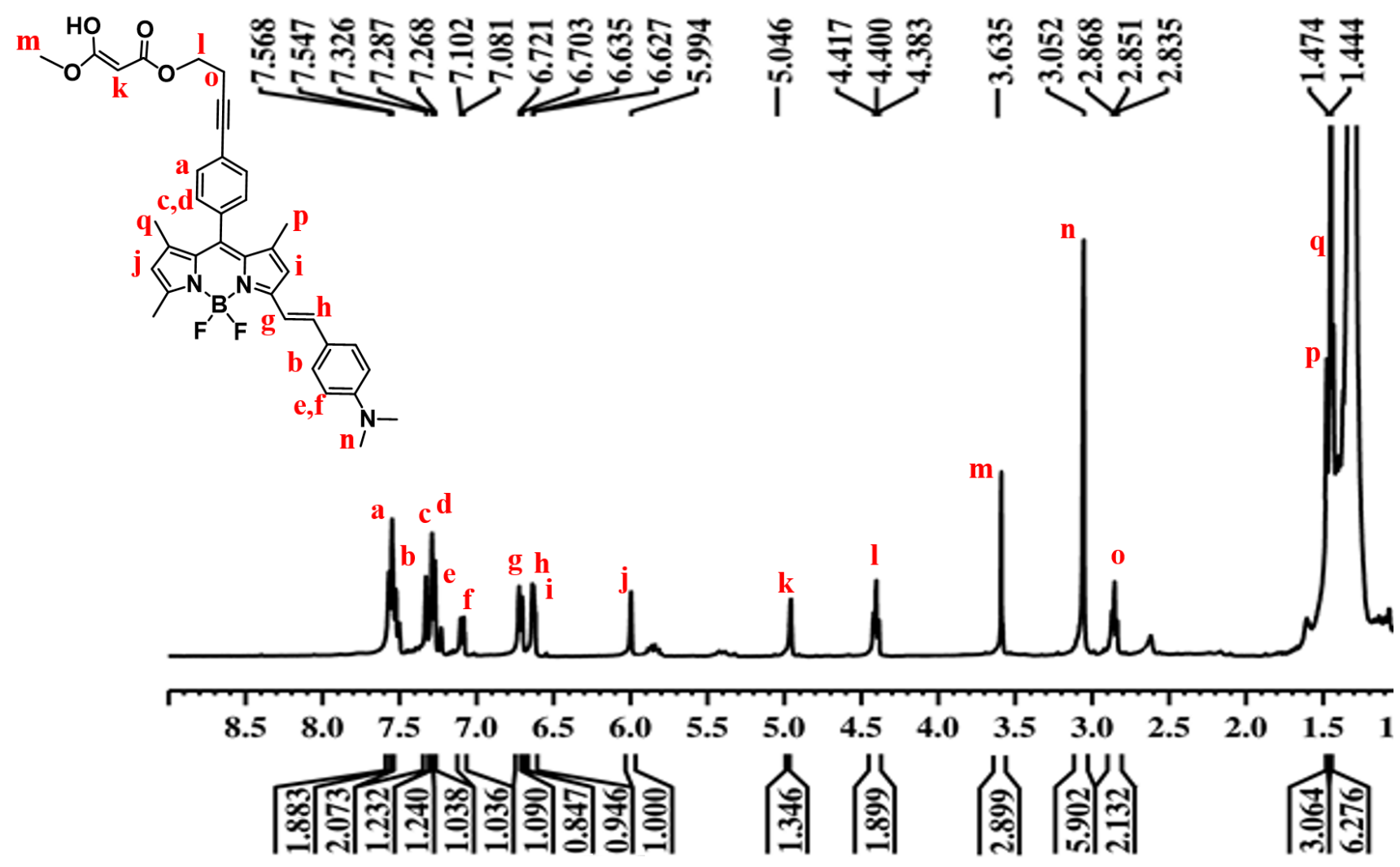

Figure S3: ${ }^{1} \mathrm{H}$ NMR spectrum of ligand HA-BOD in $\mathrm{CDCl}_{3}$. 


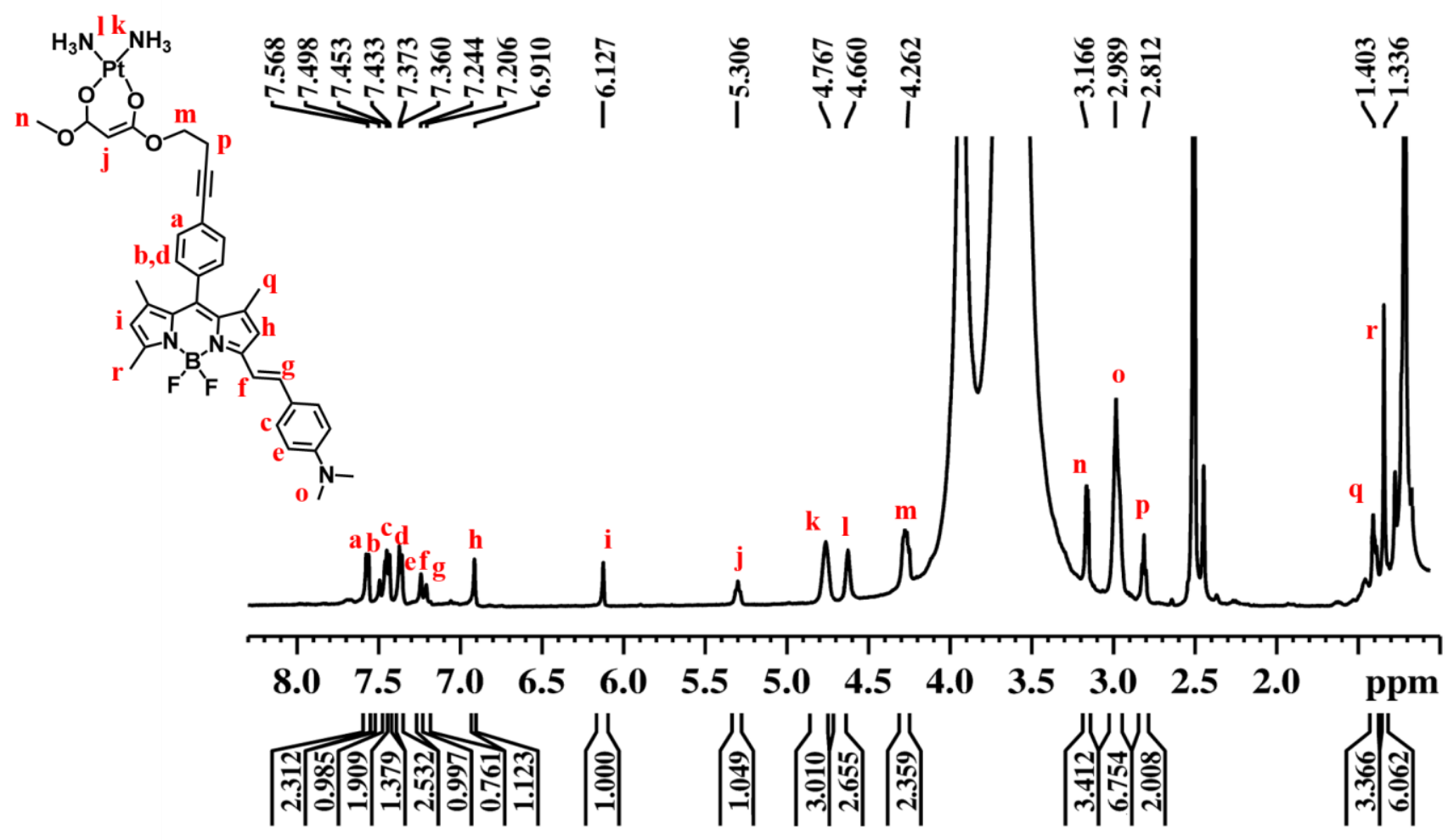

Figure S4: ${ }^{1} \mathrm{H}$ NMR spectrum of complex Pt-A-BOD in DMSO-d ${ }_{6}$. 

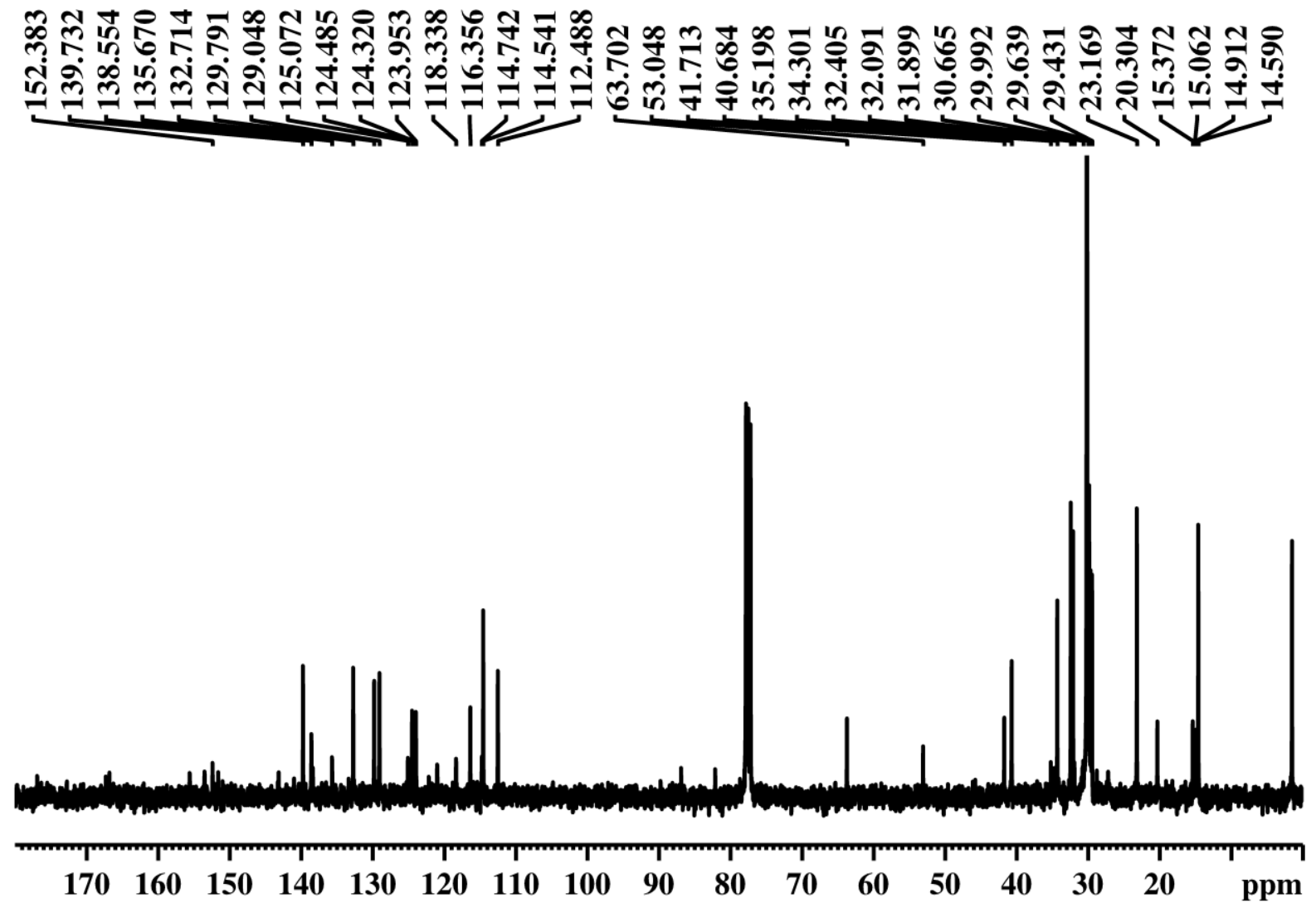

Figure S5: ${ }^{13} \mathrm{C}$ NMR spectrum of ligand HA-BOD in $\mathrm{CDCl}_{3}$. 


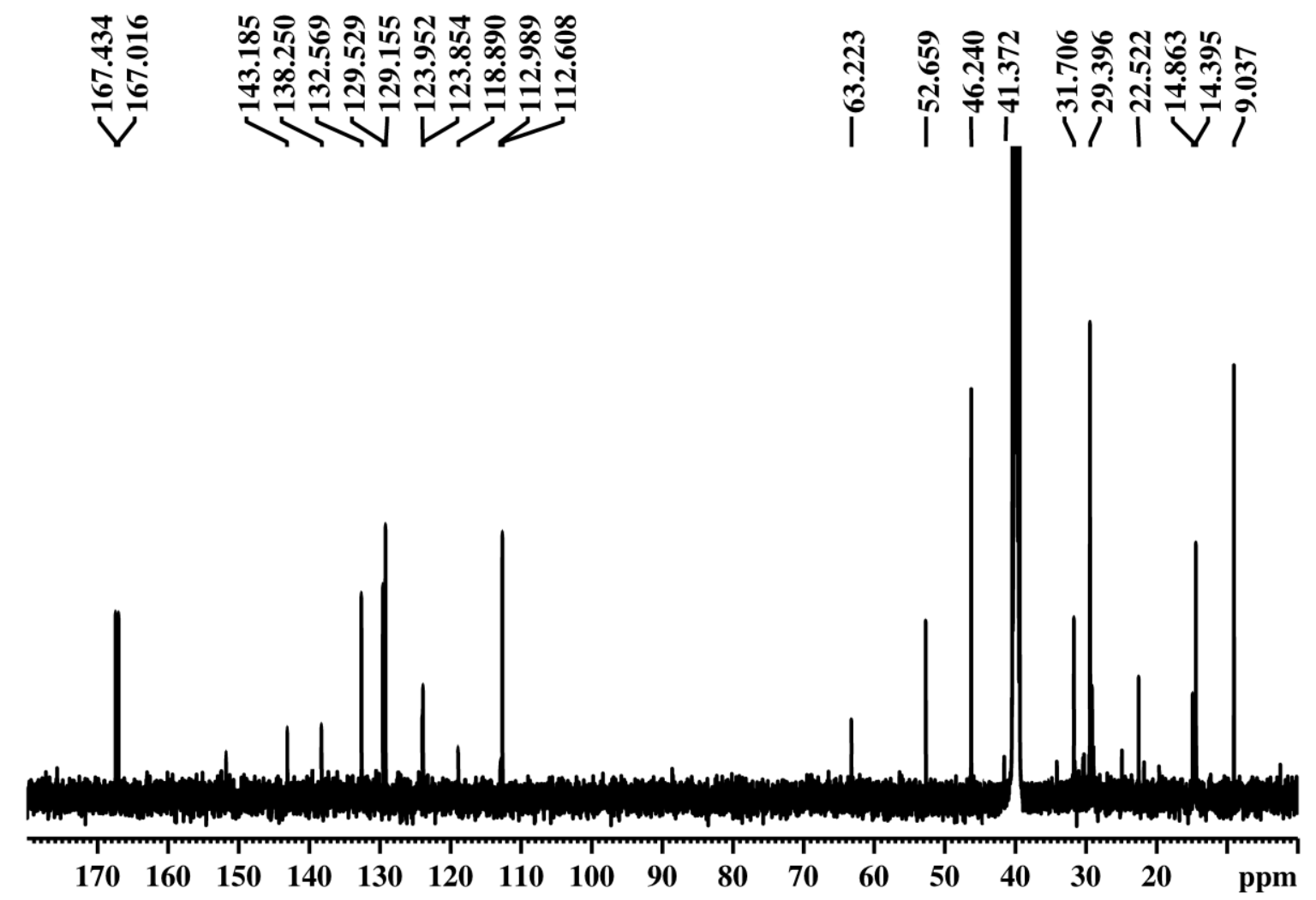

Figure S6: ${ }^{13} \mathrm{C}$ NMR spectrum of complex Pt-A-BOD in DMSO-d 6 . 

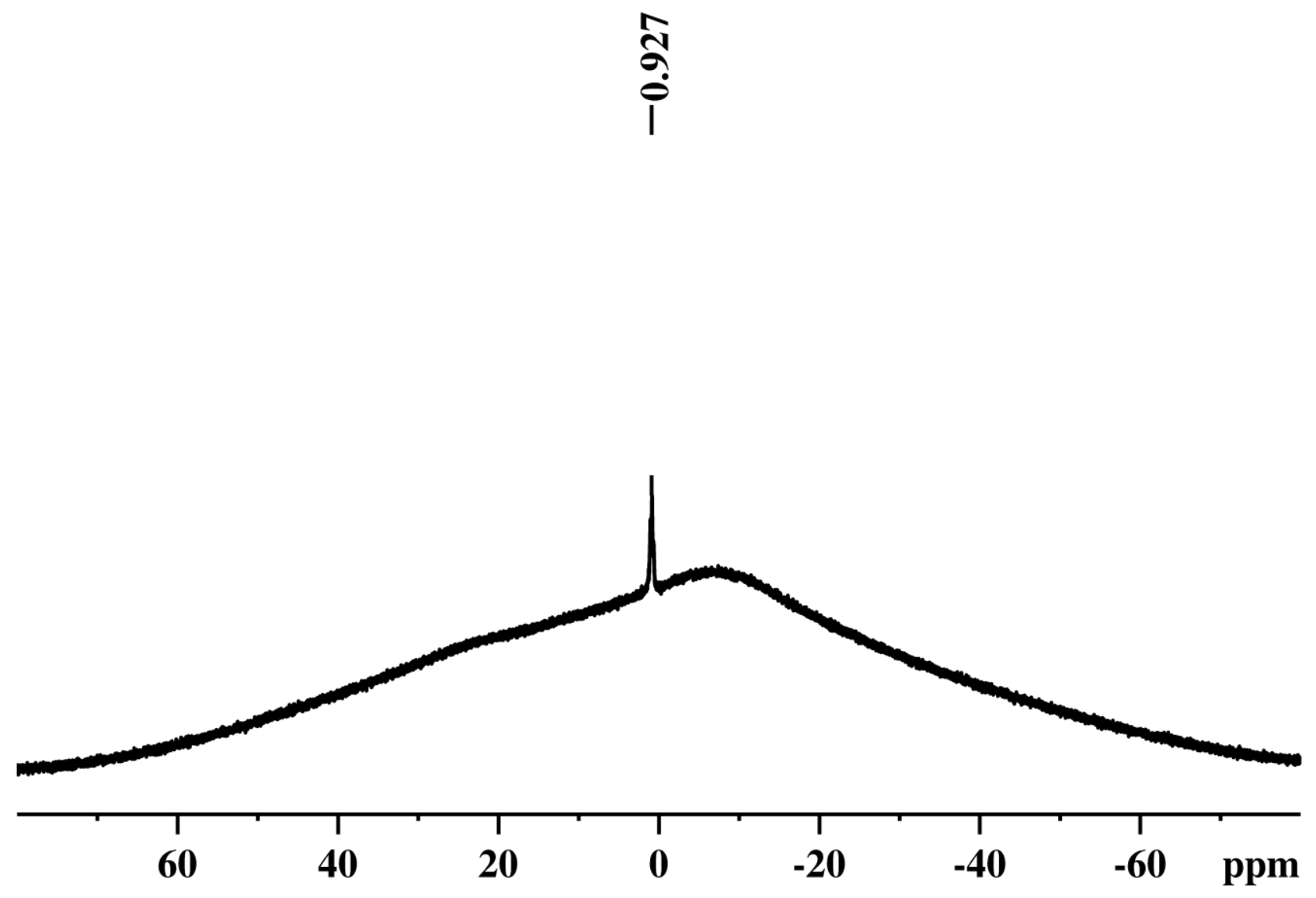

Figure S7: ${ }^{11} \mathrm{~B}$ NMR spectrum of ligand $\mathrm{HA}-\mathrm{BOD}$ in $\mathrm{CDCl}_{3}$. 

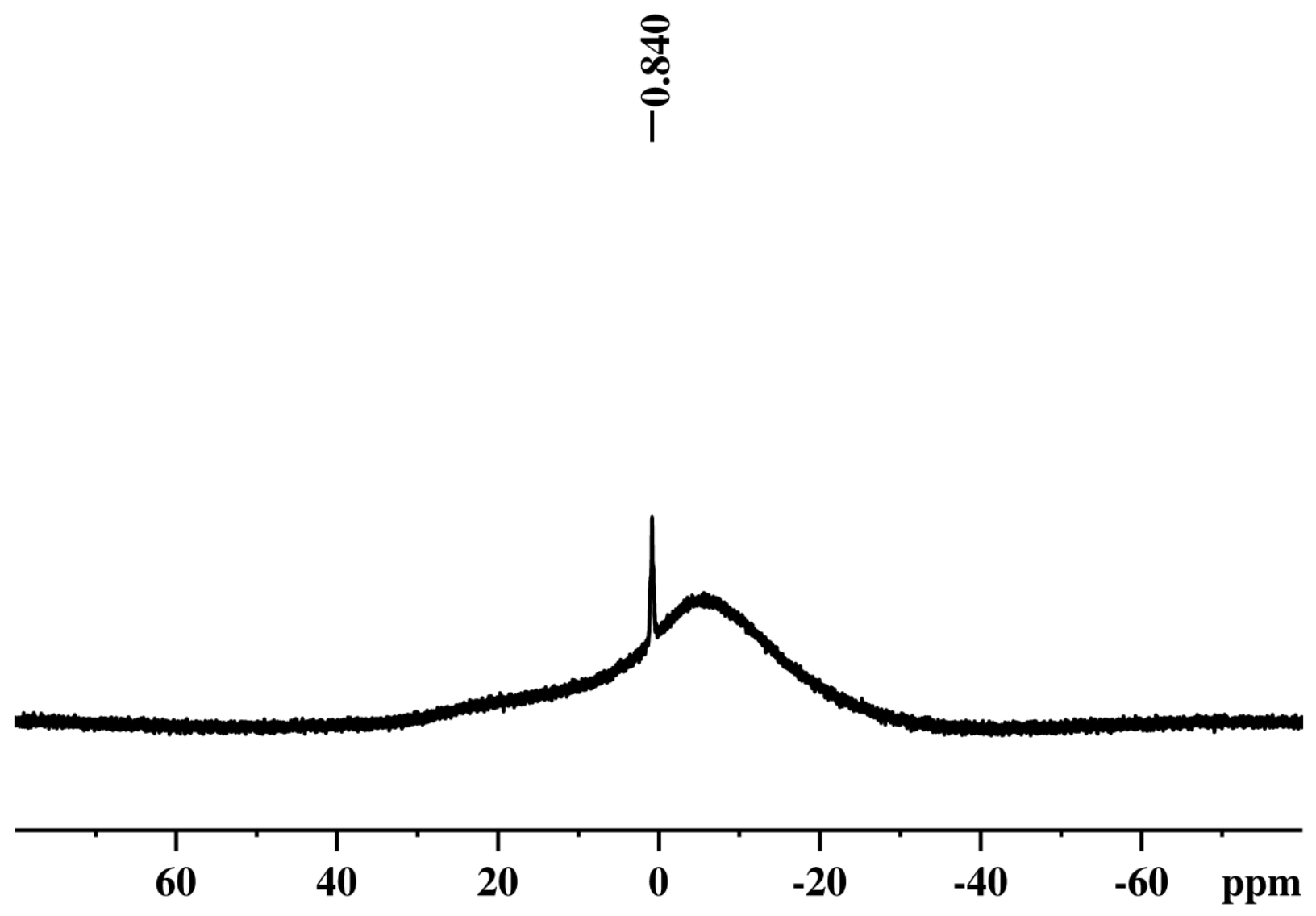

Figure S8: ${ }^{11}$ B NMR spectrum of complex Pt-A-BOD in DMSO-d . $_{\text {. }}$ 

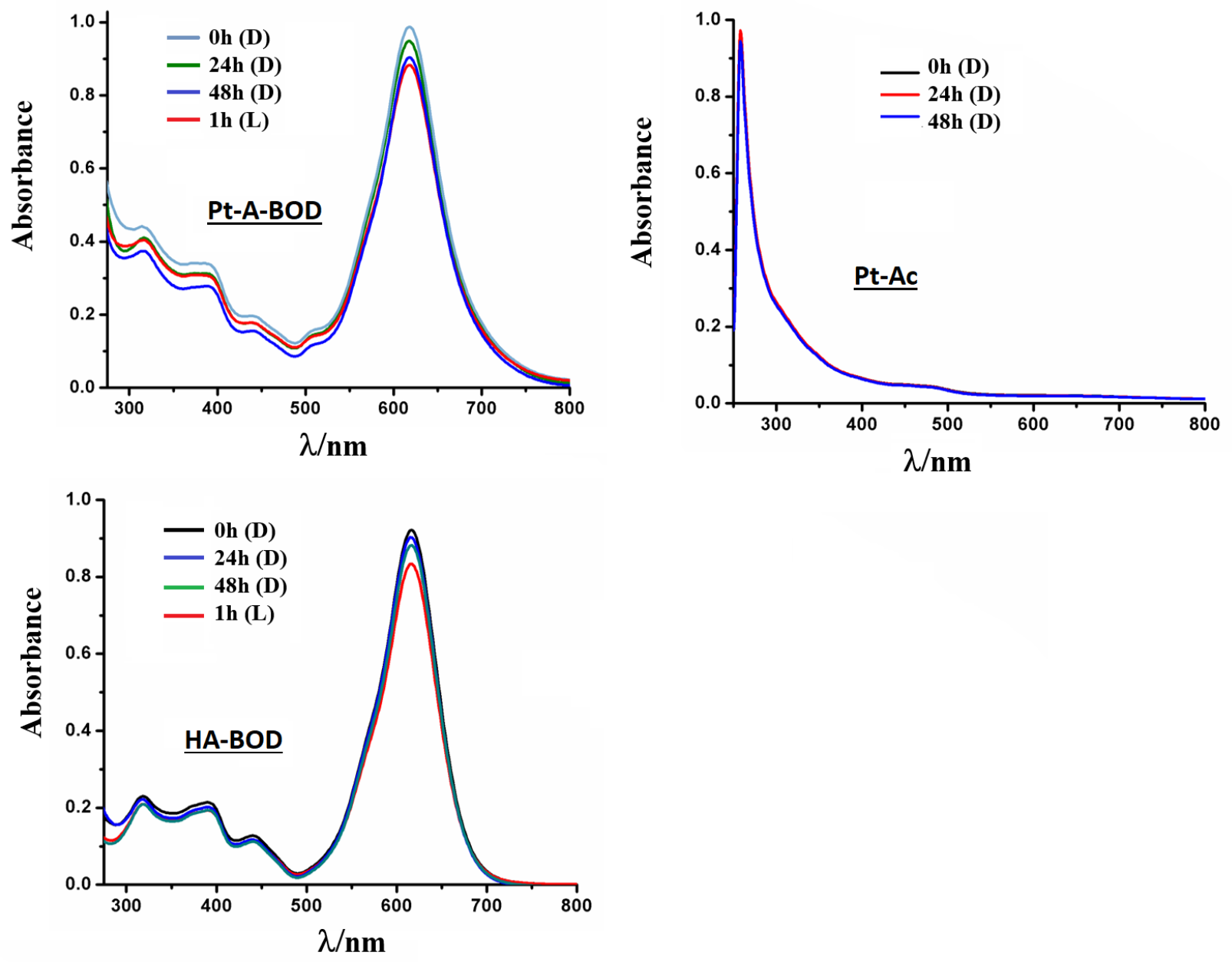

Figure S9 (a). Time dependent UV-visible spectra of the complexes Pt-A-BOD, Pt-Ac and the ligand HA-BOD in dark (D) and on light exposure (L, 600-720 nm) in 10\% DMSO/DMEM solution. 

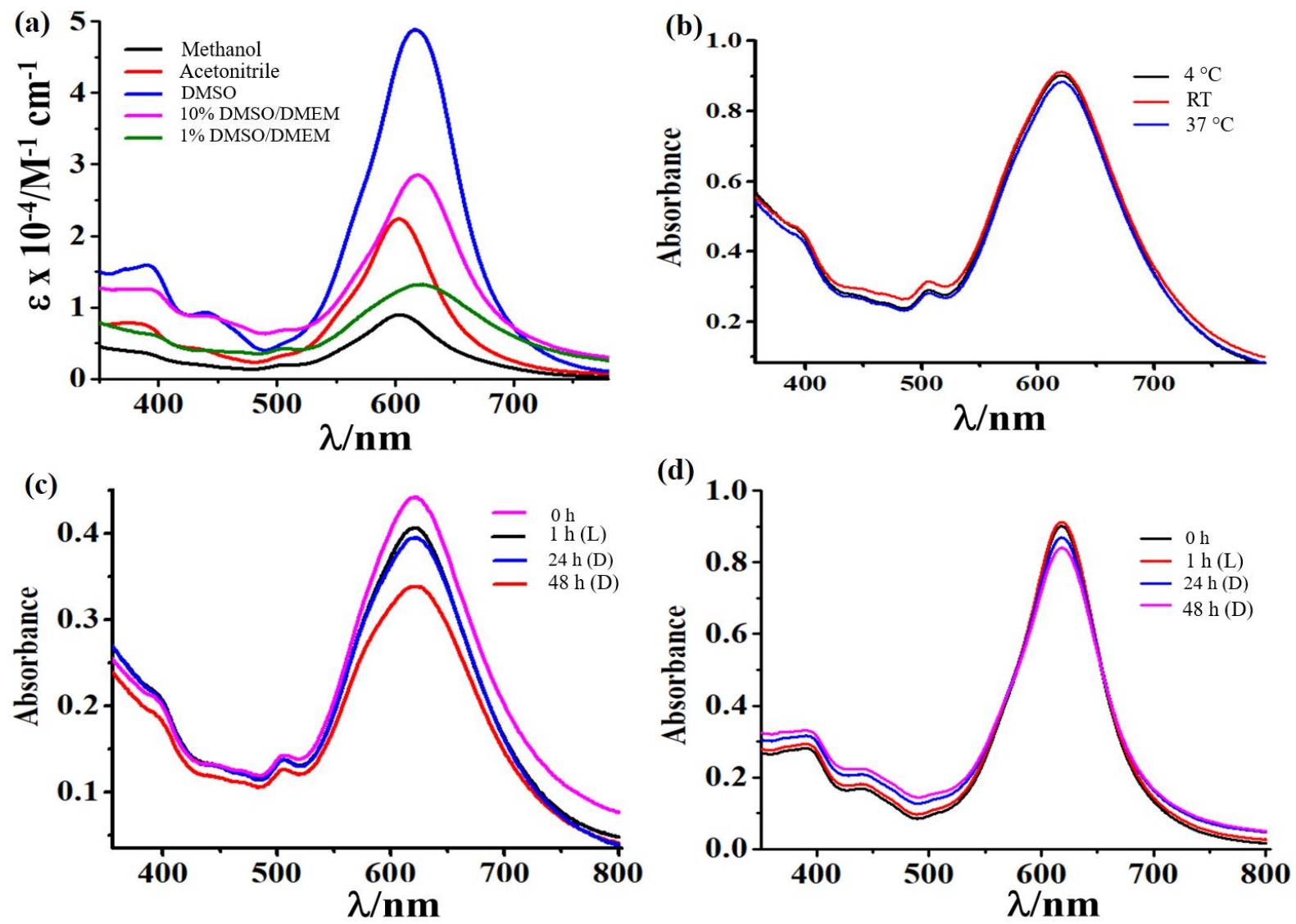

Figure S10. UV-visible spectra of the complex Pt-A-BOD in different solvents/solvent mixtures (a), temperature dependent UV-visible spectra of the complex Pt-A-BOD at RT, $4^{\circ} \mathrm{C}$ and $37^{\circ} \mathrm{C}$ for $4 \mathrm{~h}$ (b), time dependent UV-visible spectra of the complex Pt-A-BOD dark (D) and on light exposure (L, $600-720 \mathrm{~nm}$ ) in 1\% DMSO/DMEM solution (c) and 100\% DMSO (d). 

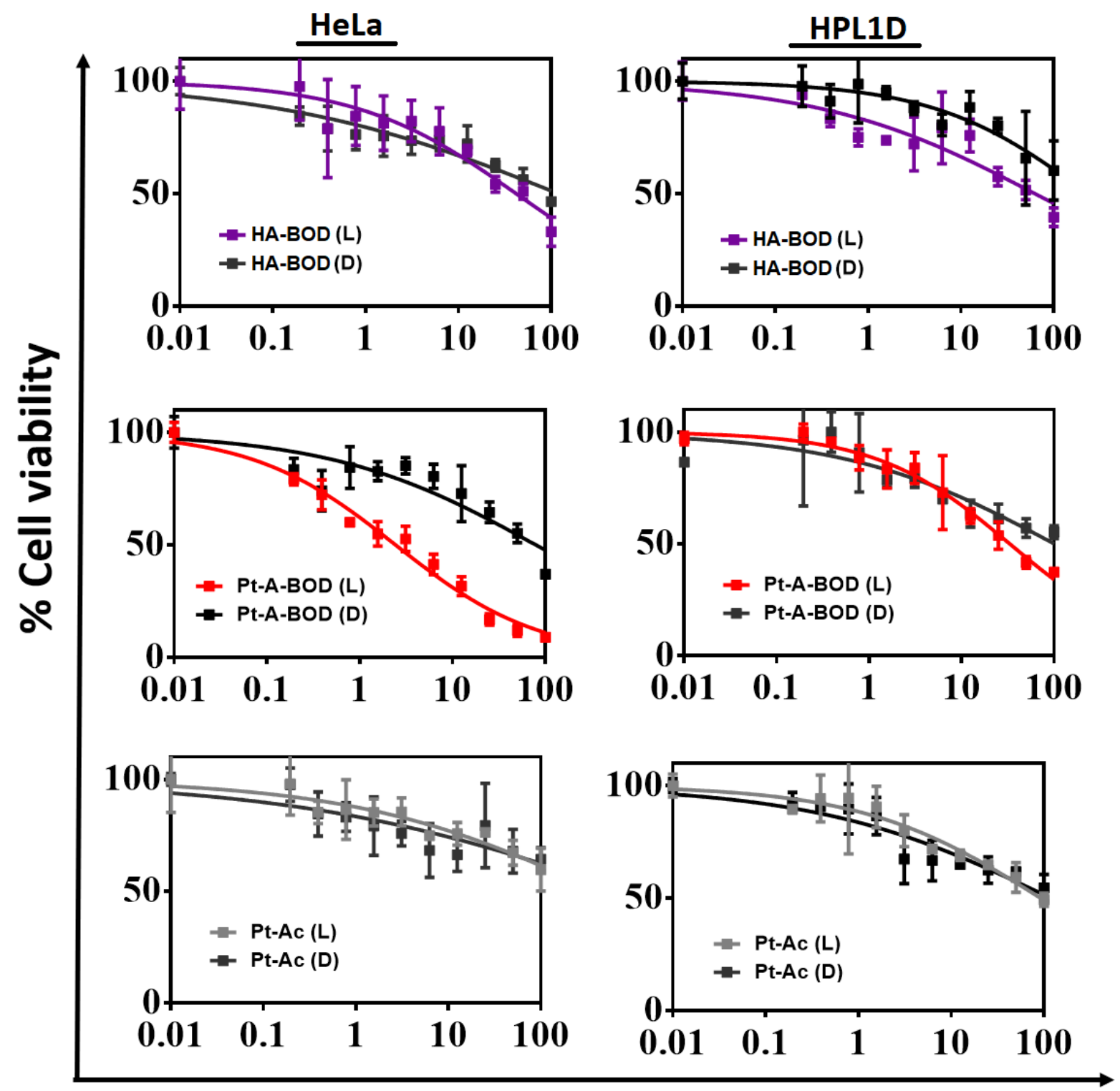

Figure S11. Cell viability plots as obtained from the MTT assay in HeLa and HPL1D cells treated with the compounds for $4 \mathrm{~h}$ initial incubation period in dark. Cells were exposed to red light $(\lambda=600-720 \mathrm{~nm}$, light dose $=30 \mathrm{~J} \mathrm{~cm}^{-2}$ ). 


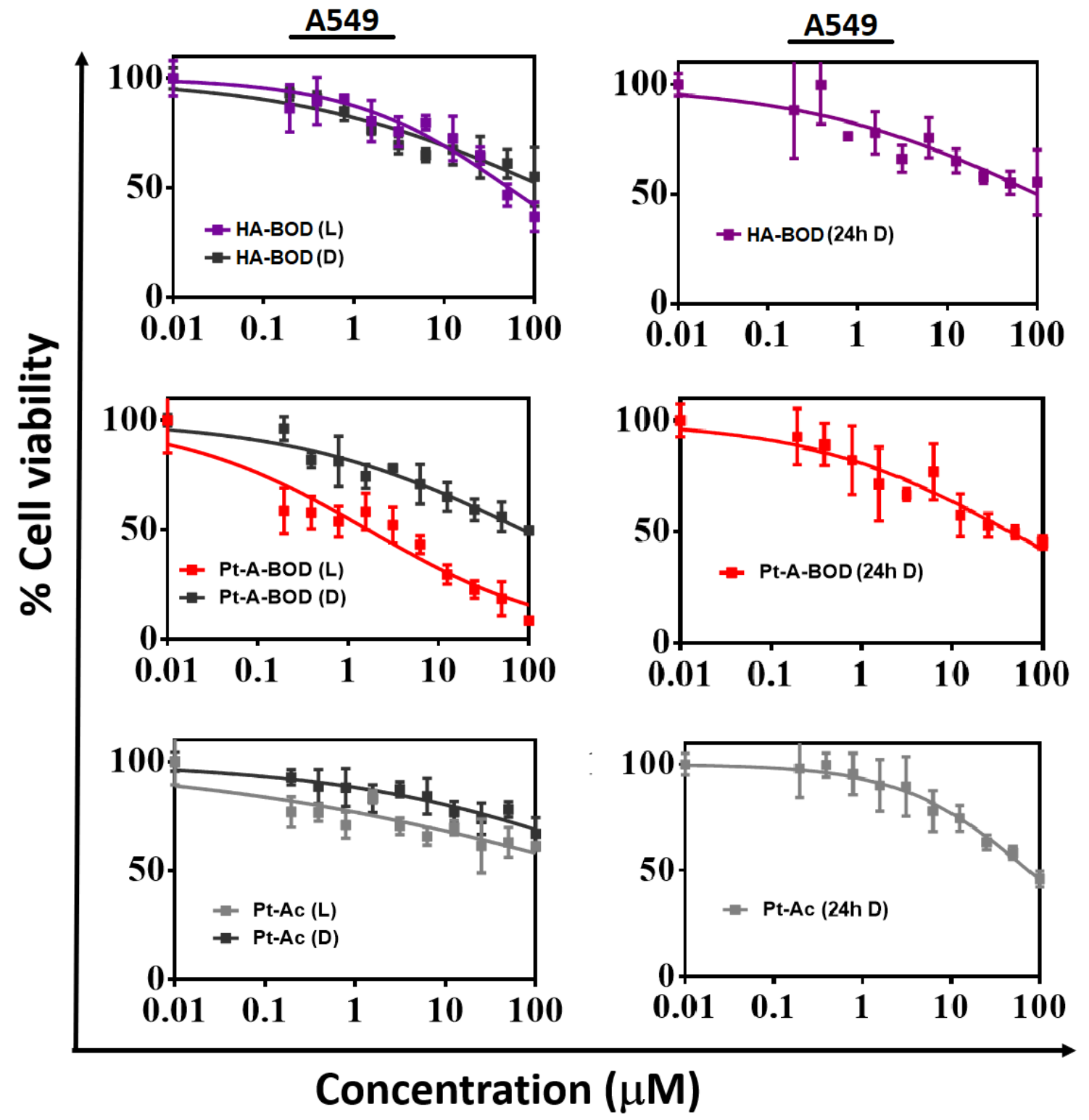

Figure S12 (a). Cell viability plots as obtained from the MTT assay in A549 cells treated with the compounds for $4 \mathrm{~h}$ initial incubation period in dark. Cells were exposed to red light $(\lambda=600-720 \mathrm{~nm}$, light dose $=30 \mathrm{~J} \mathrm{~cm}^{-2}$ ). 

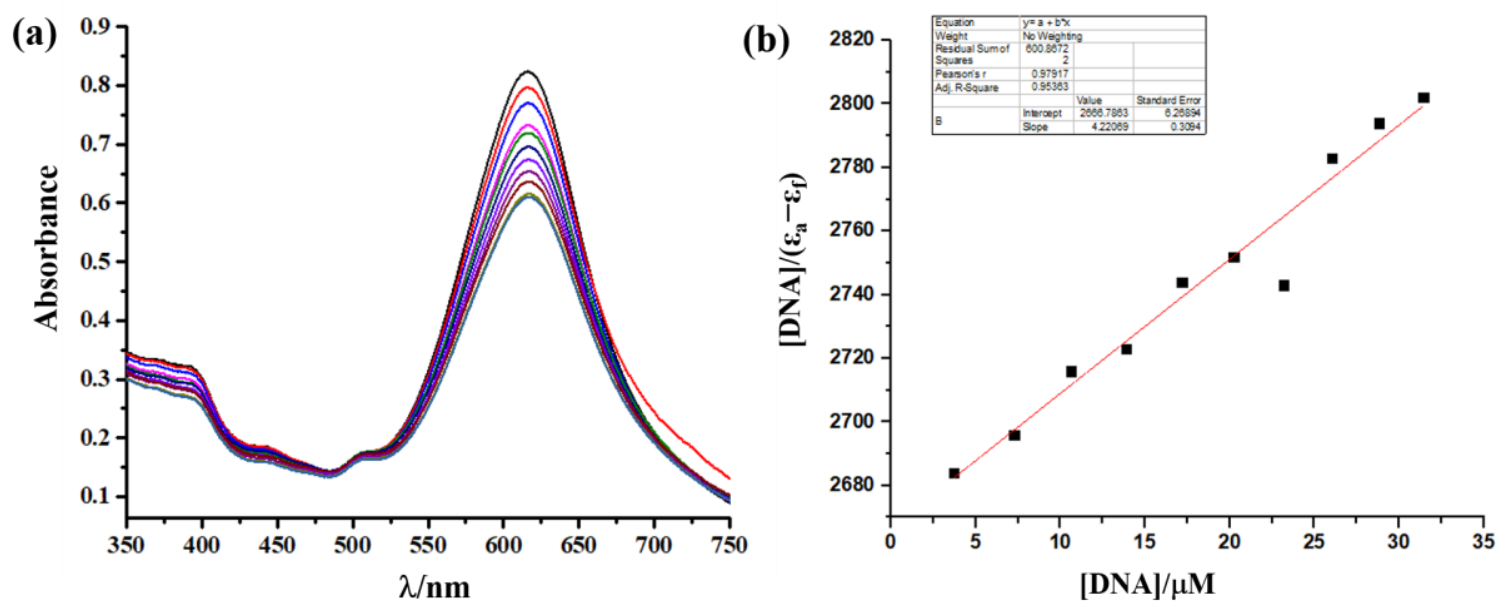

Figure S13. (a) UV- visible spectral changes observed for Pt-A-BOD on gradual addition of ct-DNA in $10 \%$ DMF-DPBS (b) Plot of [DNA] $/\left(\varepsilon_{\mathrm{a}}-\varepsilon_{\mathrm{f}}\right)$ vs. [DNA] from UV/visible titration experiments. 

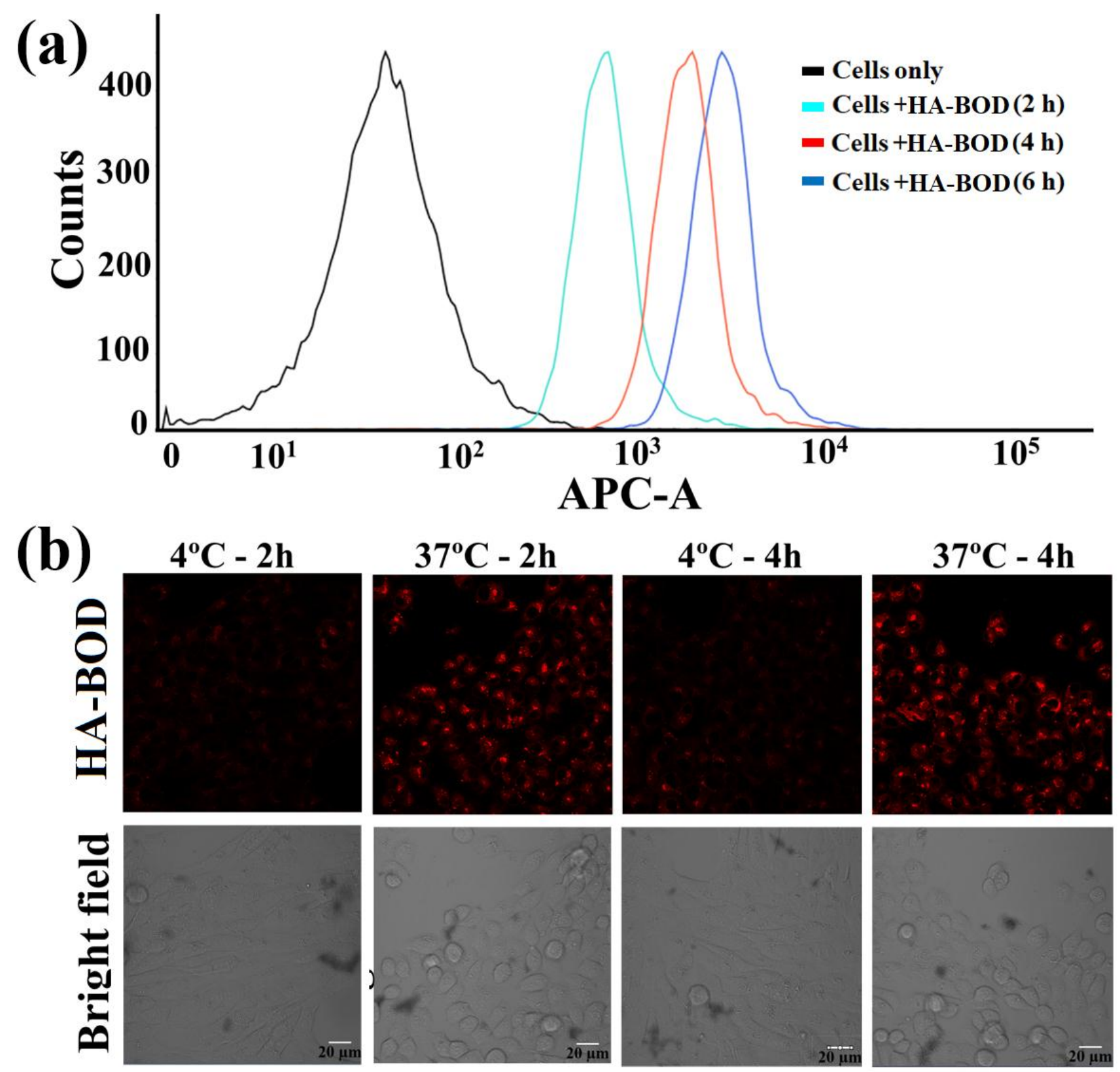

Figure S14. (a) Quantitative analysis by flow cytometry upon incubating A549 cells with ligand HABOD $(15 \mu \mathrm{M})$ at $37{ }^{\circ} \mathrm{C}$ for $4 \mathrm{~h}$, with cells untreated as a control. (b) Confocal images of HeLa and A549 cells incubated with HA-BOD $(15 \mu \mathrm{M})$ at two different temperatures, namely, $37{ }^{\circ} \mathrm{C}$ and $4{ }^{\circ} \mathrm{C}$ for 4h. Scale bar: $20 \mu \mathrm{m}$. 

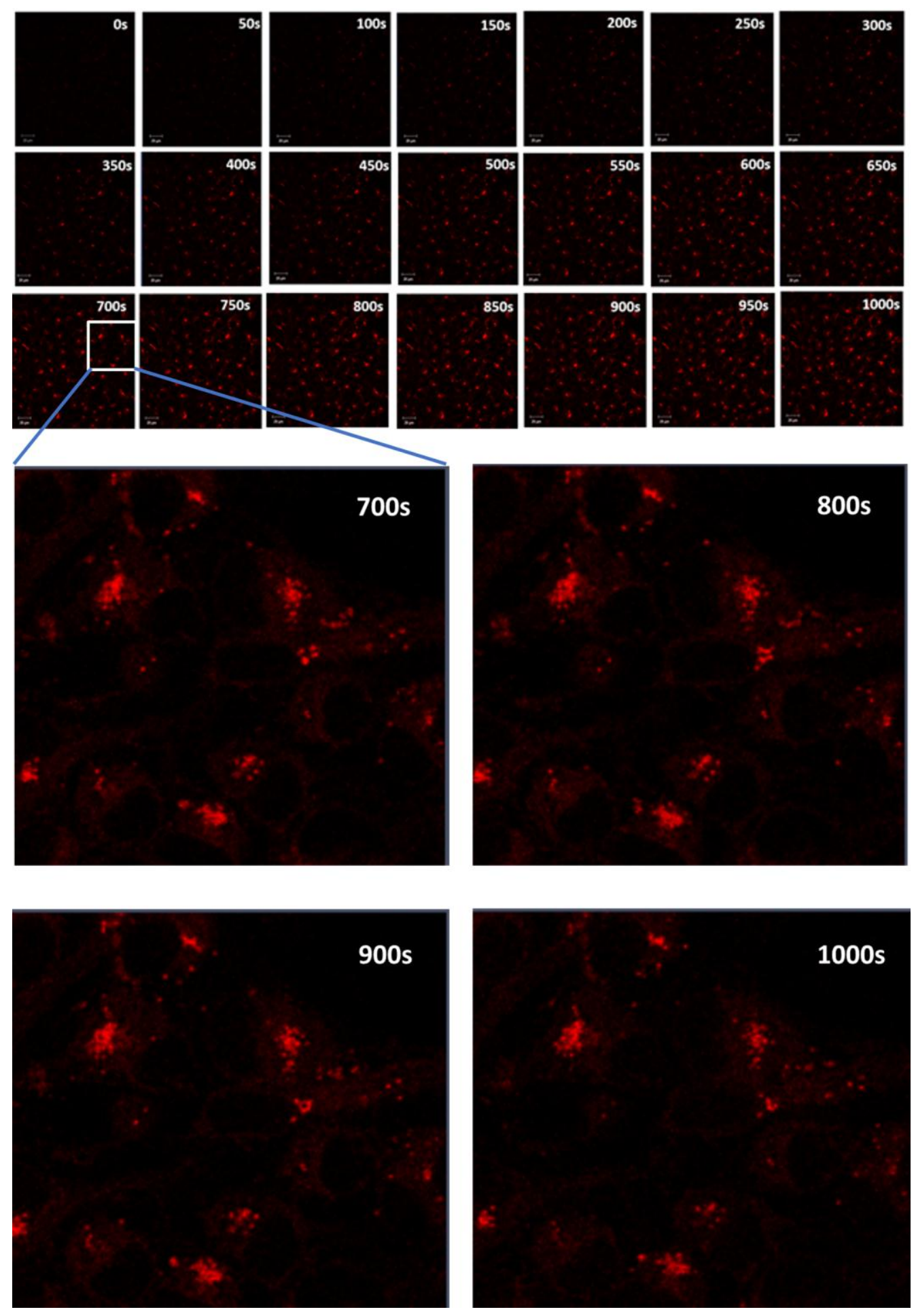

Figure S15. CLSM series images obtained from live cellular uptake of complex Pt-A-BOD $(1 \mu \mathrm{M})$ in A549 cells with no time interval with band path of $660 \mathrm{~nm}$ to $750 \mathrm{~nm}$ by using $\lambda_{\mathrm{ex}}$ of $633 \mathrm{~nm}$. 


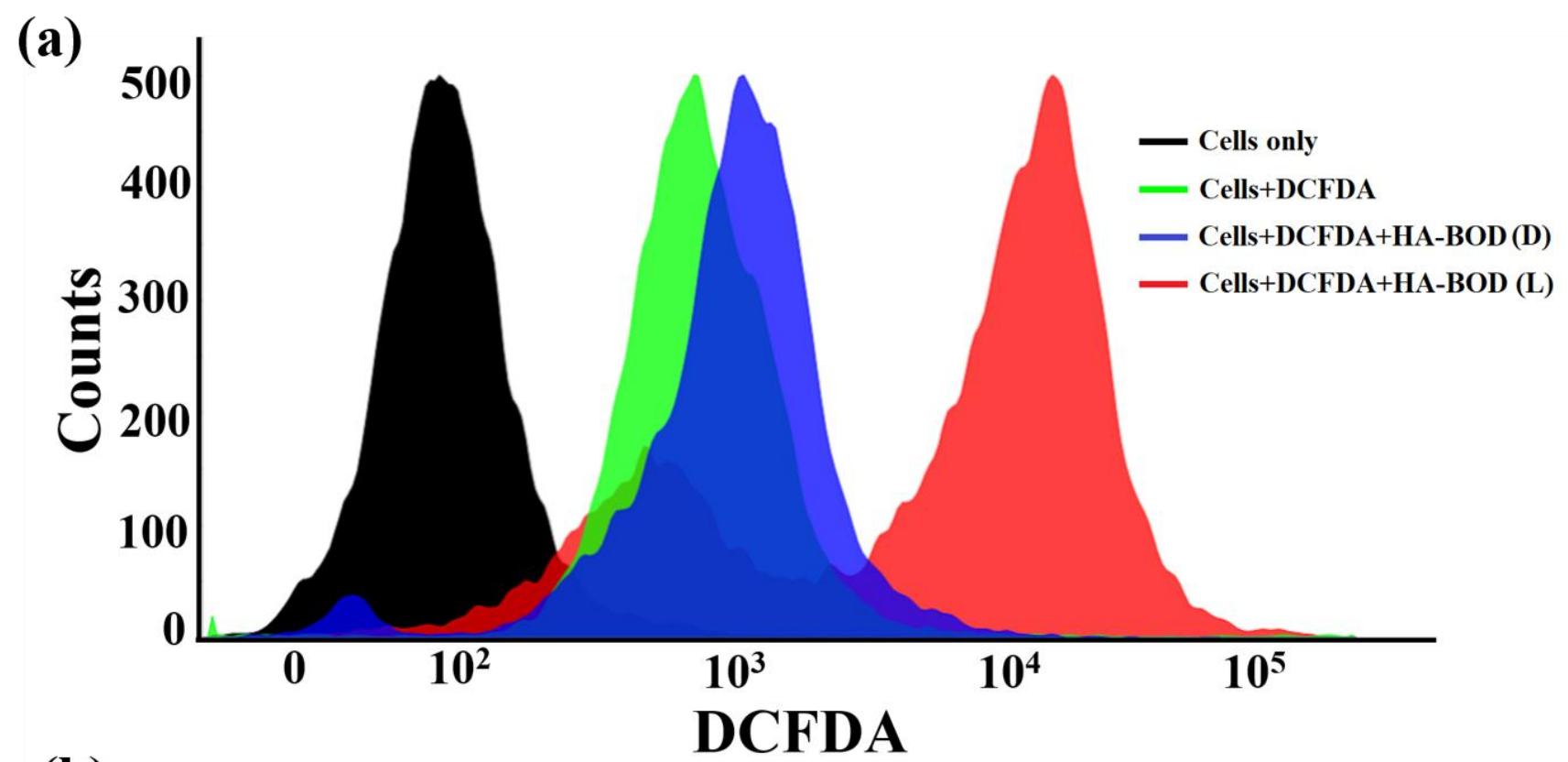

(b)

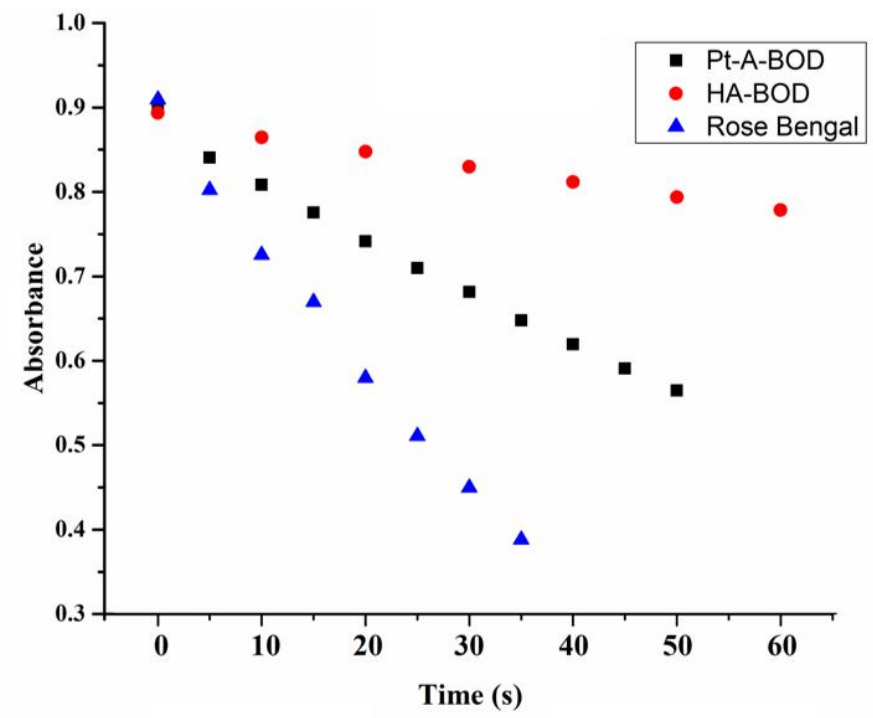

Figure S16. (a) Shift in the band position of HA-BOD $(40 \mu \mathrm{M})$ treated with DCFDA in A549 cells under red light irradiation $\left(\lambda=600-720 \mathrm{~nm}\right.$, light dose $\left.=30 \mathrm{~J} \mathrm{~cm}^{-2}\right)$ indicating the generation of cellular ROS (b) The linear plot showing a gradual decrease in absorbance of DPBF at $417 \mathrm{~nm}$ with time on light exposure. 


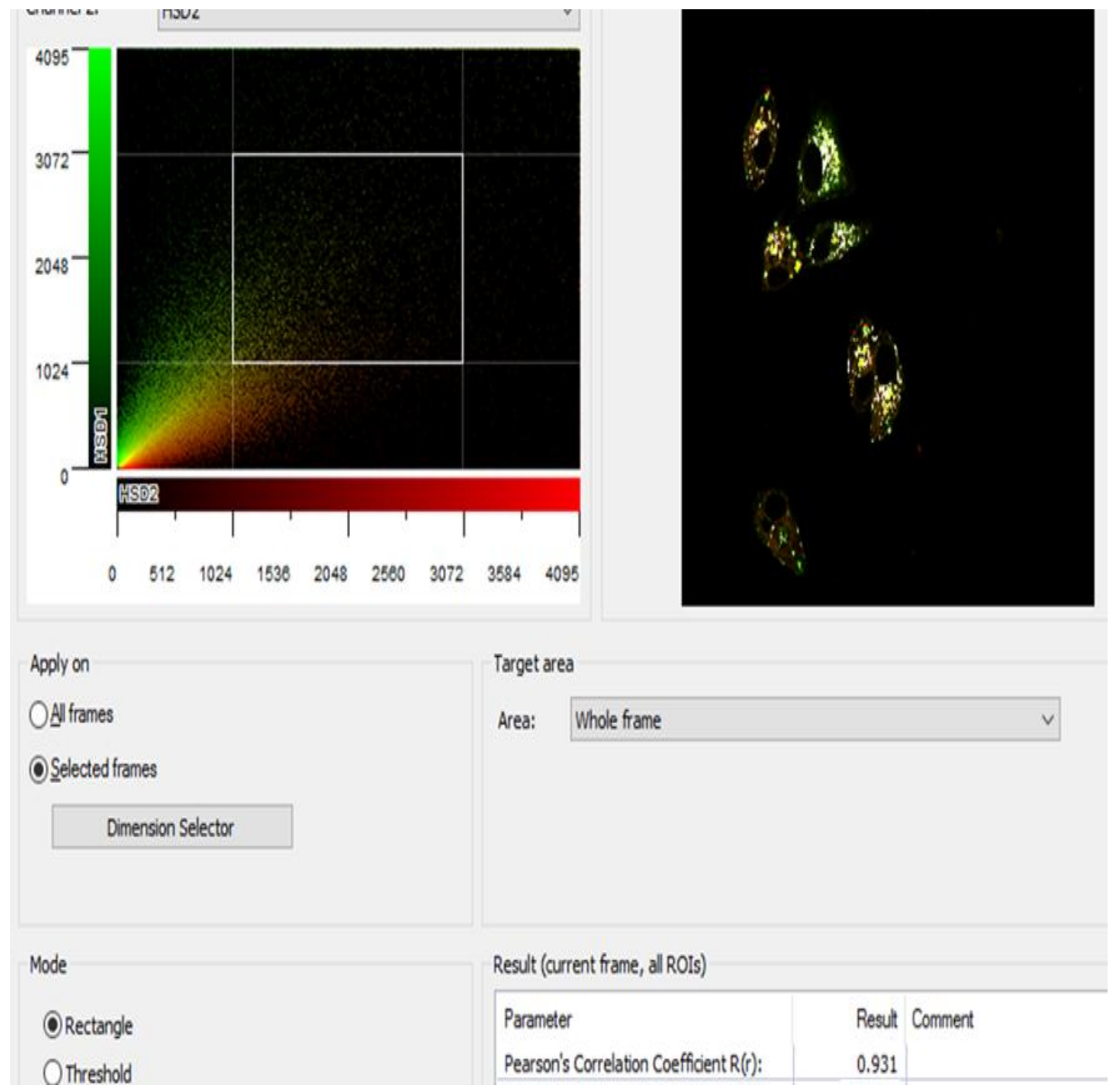

Figure S17. Scatter plot of merged green and red pixel intensities of Pt-A-BOD and mitotracker green (MTG) and their confocal merged image. Pearson's coefficient value measured is 0.931 . 
(a) Bright field

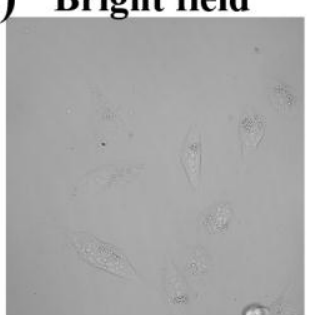

(b)
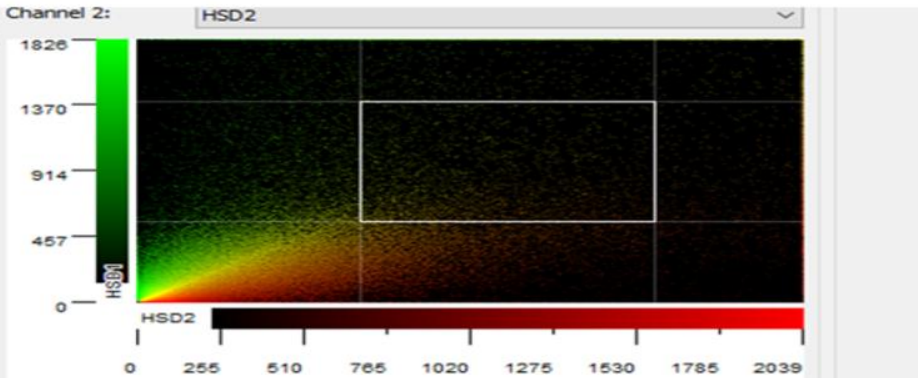

$$
\text { Apply on }
$$

All frames

OSelected frames

Dimension Selector

Mode

O Rectangle

DAPI
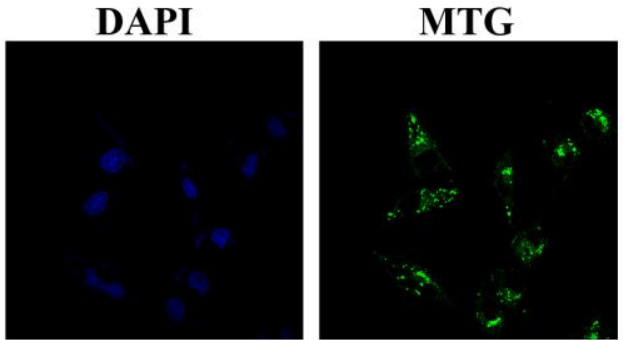

Target area

Area:

Whole frame
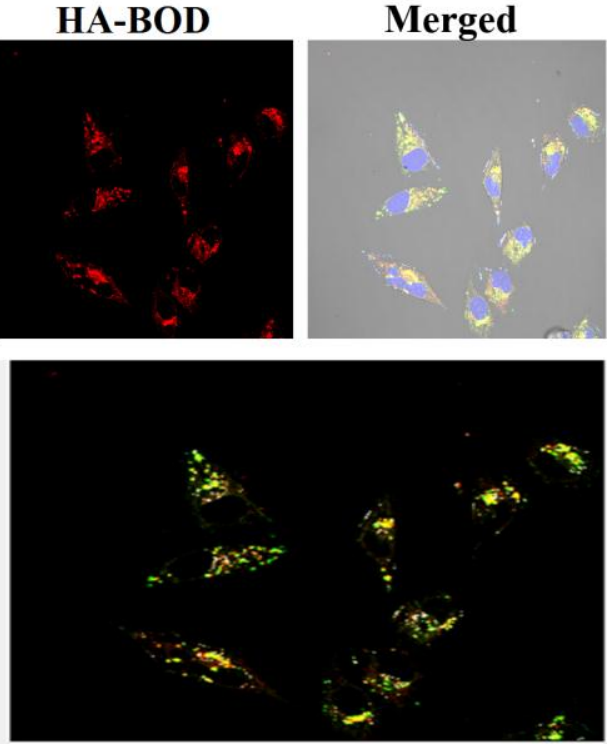

Merged

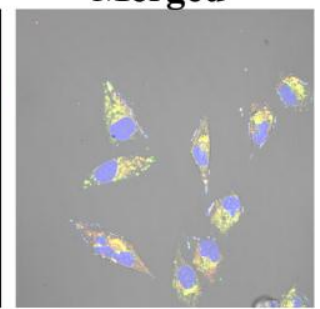

Figure S18. (a) Confocal microscopic image of ligand HA-BOD $(15 \mu \mathrm{M})$ with red emission in A549 cells on $4 \mathrm{~h}$ incubation in the dark, and on merging with mitotracker green (MTG) and DAPI showed predominant mitochondrial localization. (b) Scatter plot of merged green and red pixel intensities of HA-BOD and mitotracker green (MTG) and their merged image. Pearson's coefficient value measured is 0.939 . 

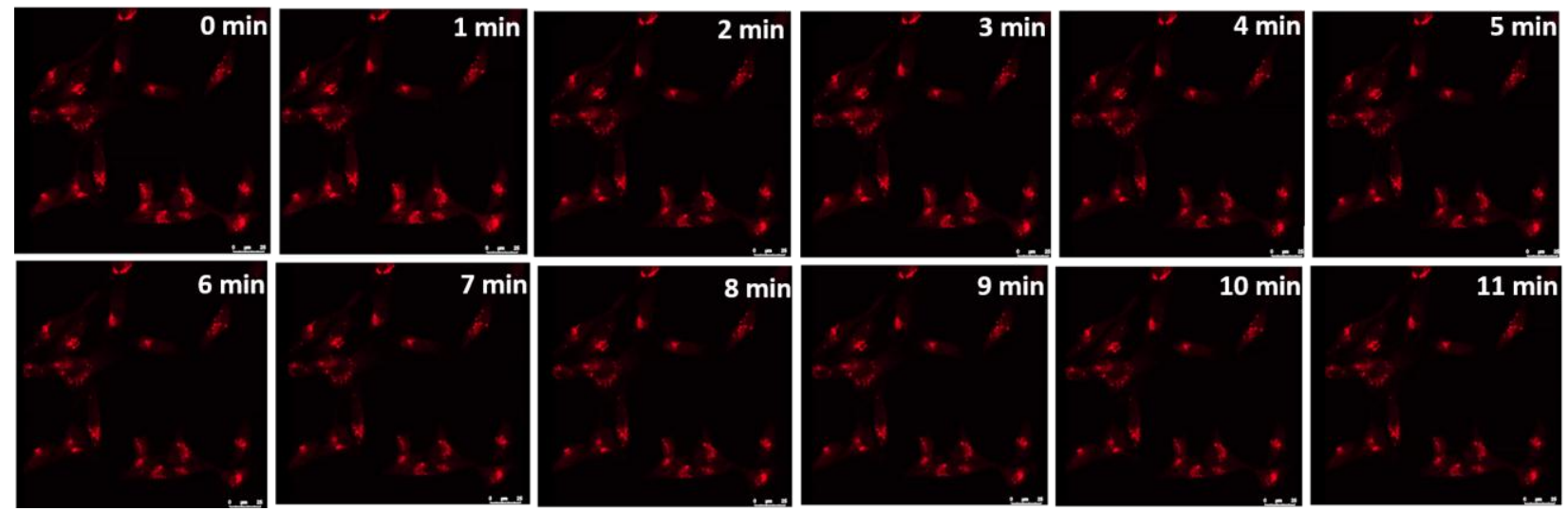

Figure S19. CLSM series images obtained from complex Pt-A-BOD $(2 \mu \mathrm{M})$ treated A549 cells at a time interval of $1 \mathrm{~min}$. Minor decrease observed in the fluorescence intensity from the first recorded image to the last image clearly indicating negligible bleaching of complex Pt-A-BOD as a dye. 


\section{Table S1. Coordinates for Optimized Geometry of ligand HA-BOD and complex Pt-A-BOD obtained from DFT Calculations using B3LYP/LANL2DZ Level of Theory for All Atoms.}

\section{Complex Pt-A-BOD}

$6 \quad 7.413761000 \quad-2.203057000 \quad 3.901925000$

$1 \quad 7.752430000 \quad-2.963247000 \quad 3.202531000$

$1 \quad 7.987561000 \quad-2.240216000 \quad 4.819248000$

$\begin{array}{llll}1 & 6.351850000 & -2.316943000 & 4.106331000\end{array}$

$\begin{array}{llll}8 & 7.686755000 & -0.859887000 & 3.364297000\end{array}$

$\begin{array}{llll}6 & 7.133483000 & -0.465828000 & 2.196790000\end{array}$

$\begin{array}{llll}6 & 7.050979000 & 1.432907000 & 0.602127000\end{array}$

$\begin{array}{llll}8 & 6.325036000 & 0.906077000 & -0.359615000\end{array}$

$\begin{array}{llll}8 & 7.473049000 & 2.706564000 & 0.415395000\end{array}$

$\begin{array}{llll}6 & 7.190787000 & 3.441983000 & -0.839717000\end{array}$

$\begin{array}{llll}1 & 8.065721000 & 4.074681000 & -0.952822000\end{array}$

$\begin{array}{llll}1 & 7.128080000 & 2.736300000 & -1.662890000\end{array}$

$\begin{array}{llll}6 & 5.929413000 & 4.307531000 & -0.716010000\end{array}$

$\begin{array}{llll}1 & 6.006583000 & 4.893732000 & 0.203648000\end{array}$

$\begin{array}{llll}1 & 5.955807000 & 5.029224000 & -1.539979000\end{array}$

$\begin{array}{llll}6 & 4.658669000 & 3.582219000 & -0.742414000\end{array}$

$\begin{array}{llll}6 & 3.596908000 & 2.999400000 & -0.754385000\end{array}$

$\begin{array}{llll}6 & 2.355458000 & 2.286854000 & -0.735269000\end{array}$

$\begin{array}{llll}6 & 1.882786000 & 1.703623000 & 0.459775000\end{array}$

$\begin{array}{llll}6 & 1.577775000 & 2.141404000 & -1.904148000\end{array}$

$\begin{array}{llll}6 & 0.678568000 & 1.002659000 & 0.479738000\end{array}$

$\begin{array}{llll}1 & 2.459330000 & 1.819512000 & 1.366941000\end{array}$

$\begin{array}{llll}6 & 0.374970000 & 1.435308000 & -1.874793000\end{array}$

$\begin{array}{llll}1 & 1.910616000 & 2.605040000 & -2.823145000\end{array}$

$\begin{array}{llll}6 & -0.091606000 & 0.856033000 & -0.684932000\end{array}$

$\begin{array}{llll}1 & 0.322558000 & 0.570936000 & 1.405501000\end{array}$

$\begin{array}{llll}1 & -0.215280000 & 1.341036000 & -2.776349000\end{array}$

$\begin{array}{llll}6 & -1.377685000 & 0.091115000 & -0.651327000\end{array}$

$\begin{array}{llll}6 & -2.570709000 & 0.741911000 & -0.354157000\end{array}$

$\begin{array}{llll}6 & -2.878702000 & 2.134754000 & -0.074320000\end{array}$ $\begin{array}{llll}6 & -4.239093000 & 2.207729000 & 0.123499000\end{array}$

$\begin{array}{llll}6 & -4.809595000 & 0.899692000 & -0.022497000\end{array}$

$1 \quad-4.790621000 \quad 3.105439000 \quad 0.341809000$

$\begin{array}{llll}6 & -1.354618000 & -1.302823000 & -0.918604000\end{array}$

$\begin{array}{llll}6 & -0.308915000 & -2.205267000 & -1.274721000\end{array}$

$\begin{array}{llll}7 & -2.544998000 & -2.050008000 & -0.861195000\end{array}$

$\begin{array}{lllll}6 & -0.899622000 & -3.468984000 & -1.420352000\end{array}$

$\begin{array}{llll}6 & -2.275620000 & -3.355610000 & -1.160061000\end{array}$

$\begin{array}{llll}1 & -0.395155000 & -4.381152000 & -1.693545000\end{array}$

$5 \quad-3.921170000 \quad-1.493538000 \quad-0.467087000$

$9 \quad-4.892962000 \quad-1.807536000 \quad-1.483148000$

$9 \quad-4.361804000 \quad-2.089915000 \quad 0.766401000$

$\begin{array}{llll}6 & -6.170839000 & 0.490402000 & 0.080368000\end{array}$

$\begin{array}{llll}1 & -6.369643000 & -0.549169000 & -0.129987000\end{array}$

$\begin{array}{llll}6 & -7.195642000 & 1.332588000 & 0.408002000\end{array}$

$\begin{array}{llll}1 & -6.961911000 & 2.374235000 & 0.609198000\end{array}$

$\begin{array}{llll}6 & -8.592810000 & 0.997179000 & 0.524408000\end{array}$

$\begin{array}{llll}6 & -9.526853000 & 2.003026000 & 0.868423000\end{array}$

$\begin{array}{llll}6 & -9.108010000 & -0.305505000 & 0.311010000\end{array}$

$\begin{array}{llll}6 & -10.879921000 & 1.743064000 & 0.991876000\end{array}$

$\begin{array}{llll}1 & -9.171090000 & 3.011809000 & 1.040457000\end{array}$

$\begin{array}{llll}6 & -10.455519000 & -0.582984000 & 0.430110000\end{array}$

$\begin{array}{llll}1 & -8.437726000 & -1.112231000 & 0.048297000\end{array}$

$\begin{array}{llll}6 & -11.390662000 & 0.434662000 & 0.774850000\end{array}$

$\begin{array}{llll}1 & -11.544777000 & 2.550051000 & 1.255772000\end{array}$

$\begin{array}{llll}1 & -10.793827000 & -1.592234000 & 0.257061000\end{array}$

$\begin{array}{llll}7 & -12.736197000 & 0.159424000 & 0.892915000\end{array}$

$6 \quad-3.322389000 \quad-4.417645000 \quad-1.177497000$

$\begin{array}{llll}1 & -3.826061000 & -4.481693000 & -0.211389000\end{array}$

$1 \quad-4.093128000 \quad-4.193471000 \quad-1.916016000$

$\begin{array}{llll}1 & -2.879664000 & -5.384915000 & -1.409733000\end{array}$ 


\begin{tabular}{|c|c|c|c|}
\hline & 1.152586000 & 66000 & -1.49 \\
\hline & 1.322837000 & -1.279622000 & -2.353890000 \\
\hline 1 & 1.611672000 & 9000 & 82000 \\
\hline & 1.667916000 & -2.87 & 52000 \\
\hline & 000 & 3.306 & -0.01 \\
\hline & 000 & 3.47 & 9000 \\
\hline & -2.503 & 7000 & 0000 \\
\hline & -1.177161000 & 3.181862000 & 0.75 \\
\hline & 6.357989000 & -1.3 & 8000 \\
\hline & 2000 & 000 & 3000 \\
\hline 1 & .082052000 & 000 & 2.445987000 \\
\hline & 5.411270000 & -0.889283000 & 50000 \\
\hline & 4.499029000 & -2.743648000 & 5000 \\
\hline & 4.819049000 & 000 & 1.03 \\
\hline 1 & 4.801514000 & 5000 & -0.57 \\
\hline 1 & 3.482594000 & 0000 & 0.112605000 \\
\hline & 4.452550000 & 0000 & -1.90 \\
\hline & 3.439 & 2000 & 5000 \\
\hline & 000 & 000 & 5000 \\
\hline 1 & 000 & 014000 & 9000 \\
\hline 6 & 3.240992000 & -1.198412000 & 0.662183000 \\
\hline 1 & -13.028976000 & -1.539621000 & -0.354631000 \\
\hline 1 & -12.805552000 & -1.914998000 & 1.363773000 \\
\hline 1 & -14.317904000 & -1.204459000 & 0.800829000 \\
\hline 6 & -13.681313000 & 1.222264000 & 1.249894000 \\
\hline 1 & -13.451457000 & 1.653587000 & 2.228031000 \\
\hline 1 & -13.680186000 & 2000 & 0.509 \\
\hline & 14.683534000 & 0.806757000 & 1.29299400 \\
\hline
\end{tabular}

\section{Ligand HA-BOD}

$\begin{array}{llll}6 & 12.264100000 & -1.888771000 & -3.336432000\end{array}$

$\begin{array}{llll}1 & 11.608690000 & -2.000022000 & -4.198393000\end{array}$

\begin{tabular}{|c|c|c|c|}
\hline 1 & 13.026796000 & -1.140710000 & -3.523032000 \\
\hline 1 & 12.712779000 & -2.852965000 & -3.104191000 \\
\hline 8 & 11.514430000 & -1.382354000 & -2.185248000 \\
\hline & 10.458199000 & -2.181901000 & -1.740200000 \\
\hline & 8.770151000 & -2.037348000 & 0.077887000 \\
\hline & 8.159519000 & -3.219483000 & -0.194842000 \\
\hline 1 & 7.409104000 & -3.363521000 & 0.411229000 \\
\hline 8 & 8.157733000 & -1.431239000 & 1.153300000 \\
\hline 6 & 8.589837000 & -0.107836000 & 1.614041000 \\
\hline 1 & 9.620287000 & -0.176428000 & 1.966982000 \\
\hline 1 & 8.531665000 & 0.596312000 & 0.783616000 \\
\hline 6 & 7.6564 & 0.292379000 & 77000 \\
\hline 1 & 7.706980000 & -0.480646000 & 4000 \\
\hline 1 & 8.0587 & 2000 & 50000 \\
\hline 6 & 6.270843000 & 0.507678000 & 2.340959000 \\
\hline 6 & 5.125886000 & 0.686034000 & 1.992583000 \\
\hline 6 & 3.772540000 & 241000 & 1.581438000 \\
\hline & 3.345244000 & 0.529060000 & 0.290020000 \\
\hline & 2.834305000 & 1.478406000 & 2.457640000 \\
\hline & 2.026280000 & 0.736208000 & -0.107331000 \\
\hline & 4.053792000 & 0.082633000 & -0.393742000 \\
\hline & 1.516834000 & 1.682020000 & 2.053766000 \\
\hline 1 & 3.147293000 & 1.766611000 & 3.451567000 \\
\hline & 1.094912000 & 1.313457000 & 0.768009000 \\
\hline 1 & 1.713245000 & 0.449803000 & -1.102482000 \\
\hline & 807653000 & 2.129919000 & 2.736977000 \\
\hline & 0.321071000 & 1.537790000 & 0.338053000 \\
\hline & -1.276339000 & 0.533707000 & 0.538725000 \\
\hline & -1.184455000 & -0.789110000 & 1.112670000 \\
\hline & -2.615051000 & 0.722787000 & 0.139182000 \\
\hline & -2.450442000 & -1.342996000 & 1.038775000 \\
\hline & -3.336971000 & -0.404366000 & 0.433366000 \\
\hline & -2.720771000 & -2.328234000 & 1.377105000 \\
\hline & -0.673343000 & 2.760559000 & -0.26517300 \\
\hline
\end{tabular}




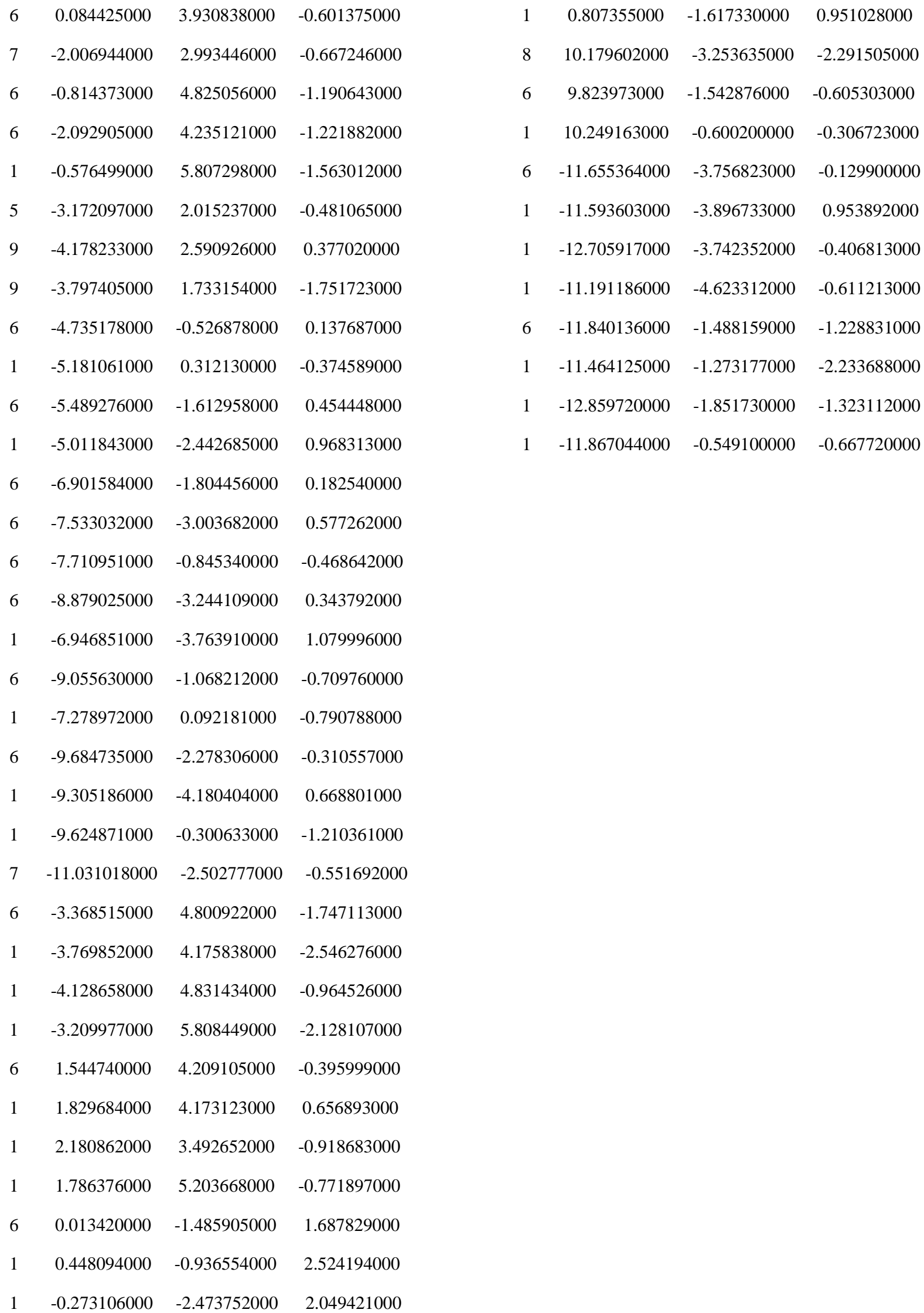




$\begin{array}{cc}\operatorname{Pt}(1)-\mathrm{N}(1) & 2.084 \\ \operatorname{Pt}(1)-\mathrm{N}(2) & 2.080 \\ \operatorname{Pt}(1)-\mathrm{O}(1) & 2.024 \\ \mathrm{Pt}(1)-\mathrm{O}(2) & 2.036 \\ \mathrm{~N}(1)-\mathrm{Pt}(1)-\mathrm{N}(2) & 99.37 \\ \mathrm{O}(1)-\mathrm{Pt}(1)-\mathrm{O}(2) & 94.15 \\ \mathrm{~N}(1)-\operatorname{Pt}(1)-\mathrm{O}(1) & 82.56 \\ \mathrm{~N}(2)-\operatorname{Pt}(1)-\mathrm{O}(2) & 83.91\end{array}$

\section{References}

1. Skehan, P.; Storeng, R.; Scudiero, D.; Monks, A.; McMahon, J.; Vistica, D.; Warren, J. T.; Bokesch, H.; Kenney, S.; Boyd, M. R. New Colorimetric Cytotoxicity Assay for AnticancerDrug Screening. J. Natl. Cancer Inst. 1990, 82, 1107-1112.

2. Ramu, V.; Gautam, S.; Kondaiah, P.; Chakravarty, A. R. Diplatinum(II) Catecholate of Photoactive Boron-Dipyrromethene for Lysosome-Targeted Photodynamic Therapy in Red Light. Inorg. Chem. 2019, 58, 9067-9075.

3. (a) Ziessel, R.; Ulrich, G.; Harriman, A.; Alamiry, M. A. H.; Stewart, B.; Retailleau, P. SolidState Gas Sensors Developed from Functional Difluoroboradiazaindacene Dyes. Chem. Eur. J. 2009, 15, 1359-1369 (b) Godoy, J.; Vives, G.; Tour, J. M. Synthesis of Highly Fluorescent BODIPY-Based Nanocars. Org. Lett., 2010, 12, 1464-1467

4. (a) Paitandi, R. P.; Mukhopadhyay, S.; Singh, R. S.; Sharma, V.; Mobin, S. M.; Pandey, D. S. Anticancer Activity of Iridium (III) Complexes Based on a Pyrazole-Appended Quinoline-Based BODIPY. Inorg. Chem. 2017, 56, 12232-12247. https://doi.org/10.1021/acs.inorgchem.7b01693. (b) Amir, M. K.; Khan, S. Z.; Hayat, F.; Hassan, A.; Butler, I. S.; Zia-ur-Rehman. Anticancer 
Activity, DNA-Binding and DNA-Denaturing Aptitude of Palladium(II) Dithiocarbamates. Inorganica Chimica Acta 2016, 451, 31-40. https://doi.org/10.1016/j.ica.2016.06.036. 